\title{
A AMPLIAÇÃO DOS CANAIS DE COMUNICAÇÃO ENTRE AS UNIVERSIDADES PÚBLICAS FEDERAIS E A SOCIEDADE: OS PORTAIS INSTITUCIONAIS COMO MECANISMOS PARA IMPLEMENTAR UM NOVO MODELO DE GOVERNANÇA.
}

\section{LA AMPLIACIÓN DE LOS CANALES DE COMUNICACIÓN ENTRE LAS UNIVERSIDADES PÚBLICAS FEDERALES Y LA SOCIEDAD: LOS PORTALES INSITUCIONALES COMO MECANISMOS PARA IMPLEMENTAR UN NUEVO MODELO DE GOBERNANZA.}

\author{
${ }^{1}$ Priscila Valduga Dinarte \\ ${ }^{2}$ Rosane Leal Da Silva
}

\section{RESUMO}

As tecnologias da informação e comunicação possibilitaram que o governo oportunizasse novas formas de interação com os cidadãos. Nesse sentido que Administração Pública, ao disponibilizar canais de comunicação nas páginas das universidades federais, democratiza esse espaço, visando a governança. Nesse diapasão, o objetivo deste trabalho é analisar a implementação da Lei de Acesso à Informação nos portais das universidades federais no que diz respeito aos canais de comunicação. Visando ao cumprimento de tal escopo, como método de abordagem foi adotado o dedutivo, uma vez que parte de uma concepção geral, ao trabalhar com conceitos como governo eletrônico, governança, direito de acesso à informação, para culminar na análise em específico dos portais das universidades federais. Como método de procedimento foi adotado o monográfico, em vista da pesquisa nos portais dessas instituições. Aliado a esses, como técnicas de pesquisa foram utilizadas a observação direta, estruturada e não participativa, bem como a bibliográfica ao se valer de autores para elucidar e embasar a temática. Conclui-se que ainda há um longo caminho a ser percorrido para que as universidades federais públicas brasileiras efetivamente ingressem na era do acesso, uma vez que a implementação da LAI nos espaços acadêmicos ainda é incipiente.

Palavras-chave: Governo eletrônico, Governança, Lei de acesso à informação, Universidades federais brasileiras

\begin{abstract}
Las tecnologías de información y comunicación posibilitaron que el gobierno ponga nuevas formas de interacción con los ciudadanos. En este sentido, que la Administración Pública electrónico al colocar canales de comunicación en las páginas de las universidades federales, democratiza este espacio, mirando a la gobernanza. En este diapasón, el objetivo de este trabajo es analizar la implementación de la Ley de Acceso a la Información en los portales de las universidades federales no que dice respeto a los medios de comunicación. Visando el cumplimiento de tal escopo, como método de abordaje fue adoptado el deductivo, una vez que se parte de una concepción general, al trabajar con conceptos como gobierno electrónico, gobernanza, derecho de acceso a la información, para culminar en el análisis en específico de las páginas de las universidades federales. Como método de procedimiento fue tomado el monográfico, en vista de la pesquisa en las páginas de esas instituciones. Además, como técnicas de pesquisa fueron utilizadas la observación directa, estructurada y no participante, aún la bibliográfica, pues se vale de autores para esclarecer y embazar la temática. Fue concluso que aún hay un largo camino a ser recorrido para que las universidades federales públicas brasileñas efectivamente adentren en la era del acceso, una vez que la implementación de la LAI en los espacios académicos aún está en inicio.
\end{abstract}

Keywords: Gobierno electrónico, Gobernanza, Ley de acceso a la información, Universidades federales brasileñas

\footnotetext{
${ }^{1}$ Mestre pelo Programa de Pós-Graduação em Direito pela Universidade Federal de Santa Maria - UFSM, Rio Grande do Sul, (Brasil). E-mail: priduga@ hotmail.com

${ }^{2}$ Doutora em Direito pela Universidade Federal de Santa Catarina - UFSC, Florianópolis, Santa Catarina, (Brasil). Professora Adjunta da Universidade Federal de Santa Maria - UFSM, nos cursos de Graduação e Mestrado em Direito. E-mail: rolealdasilva@gmail.com
} 


\section{INTRODUÇÃO}

O advento das tecnologias da informação e comunicação (TIC) possibilitou que o governo buscasse novas formas de interação com a população. Surge, portanto, o governo eletrônico, na medida em que disponibiliza informação e serviços através da Internet. Ocorre que, além da informatização de processos se faz necessário repensar toda a estrutura da Administração Pública, passando de um governo para uma governança eletrônica. Termo este usado para designar processos governamentais voltados totalmente ao bem-estar e anseio dos cidadãos.

Considerando esse contexto de novas formações e percepções das ações governamentais no mundo virtual e de que forma é possível se chegar a uma governança também nesse âmbito, questiona-se: é possível afirmar que as universidades federais cumprem as determinações feitas pela Lei de Acesso à Informação, tendo implementado em seus portais institucionais canais de comunicação que oportunizem a participação social naquelas instituições e permitam o exercício do controle social?

O objetivo deste trabalho, portanto, é analisar a implementação da Lei de Acesso à Informação nos portais das universidades federais no que diz respeito aos canais de comunicação, como Fale Conosco, Ouvidoria e e-SIC. Para cumprir tal intento, optou-se por utilizar como método de abordagem o dedutivo, dentro de uma lógica descendente, pois partese de concepções gerais acerca de governo eletrônico, governança, direito de acesso à informação para se chegar à análise dos portais das universidades federais. Como método de procedimento foi adotado o monográfico, em vista da pesquisa nos sites dessas instituições. Aliado a esses, como técnicas de pesquisa foram utilizadas a observação direta, estruturada e não participativa, bem como a pesquisa bibliográfica, especialmente porque para a elaboração do artigo foram utilizados autores que tratam especificamente dos temas em discussão.

Dividiu-se o trabalho em três partes para melhor compreensão do assunto. Na primeira parte intitulada "Do governo eletrônico à governança: um novo olhar sobre a Administração Pública na sociedade em rede", buscou-se apresentar o conceito de governo eletrônico e como este se caracteriza, bem como o de governança, de modo a perceber como este último deve nortear as ações governamentais no mundo virtual. No segundo tópico denominado "O direito de acesso à informação nas universidades públicas brasileiras como mecanismo para democratizar as instituições de ensino", trabalha-se com aspectos como o direito de acesso à informação, os dispositivos referentes aos canais de comunicação na Lei 12.527 de 2011 e como as autarquias, no caso as universidades federais, devem implementar o que está 
prescrito na LAI. Por último, no título “Análise dos portais das universidades federais: os canais de comunicação como fator da implementação da governança", apresenta-se a análise dos dados sobre as páginas das universidades federais a respeito dos canais de comunicação, como forma de mapear o estado da questão nessa seara.

\section{DO GOVERNO ELETRÔNICO À GOVERNANÇA: UM NOVO OLHAR SOBRE A ADMINISTRAÇÃO PÚBLICA NA SOCIEDADE EM REDE.}

Com o advento das tecnologias de informação e comunicação, vários setores da vida em sociedade e da vida privada modificaram-se. O meio utilizado para desempenhar determinados atos ou atividades agora é a Internet. Esse perpassar da Internet pelos setores da vida humana é destacada por Ivoskus (2008, p.16-17) quando leciona que o cidadão digital tem “[...] su identidad, su trabajo, su vida social, sus juegos, sus transacciones económicas, su relación en el mundo exterior y con las obligaciones cotidianas pasan, directa o transversalmente, por Internet o por alguna herramienta relacionada con ella". Vale destacar que "[...] a Internet parece ter um efeito positivo na interação social e tende a aumentar o grau de exposição a outras fontes de informação" (CASTELLS, 2004, p.151).

Ainda, em vista da estrutura da Internet, organizada por meio de nós interconectados que permitem ligações entre os agentes que atuam no ambiente virtual, que Manuel Castells (1999, p.24) denominou a sociedade atual de "em rede". Esta nova conformação social é caracterizada pelos seus fluxos, pela possibilidade crescente de interação dos agentes e pelas inovações no campo das comunicações globais (LASH, 2005, p.50).

As possibilidades de interação são tão promissoras que esta tecnologia passou a ser utilizada, também, para recriar o espaço público ${ }^{1}$. Ciente dessas novas possibilidades, o poder

\footnotetext{
${ }^{1}$ Nesse sentido, Luiz Ademir de Oliveira e Adélia Barroso Fernandes, ao analisarem o pensamento de Habermas sobre esfera pública explicam que para ele a esfera pública "pode ser descrita como uma rede adequada para comunicação de conteúdos, tomadas de posições; nela, os fluxos comunicacionais são filtrados e sintetizados, a ponto de se condensarem em opiniões públicas enfeixadas em temas específicos. Dizendo mais claramente, dada a fluidez e dispersão do fluxo comunicativo, a esfera pública tende a absorver aqueles fluxos que são mais tematizados" (2011, p.127). Avançando um pouco mais o seu raciocínio, os autores explicam que "a esfera pública é vista como um fórum importante para onde discussões e debates de questões sociais relevantes são trazidos à luz por indivíduos e coletividades, inclusive por aqueles que eventualmente sintam-se excluídos. Na esfera pública, as minorias tentam defender-se da cultura majoritária, contestando a validade do autoentendimento coletivo, e se esforçando para convencer espaços públicos amplos de persistência e justeza de suas reivindicações. É nesse espaço, possibilitado pela comunicação, que sujeitos vão colocar seus pontos de vista, suas experiências e perspectivas do que se acha justo e tentar convencer os outros da validade de seus propósitos" (2011, p.126). Nessa mesma linha de raciocínio, Marcelo Gruman disserta afirmando que "nos dias de hoje, espaço público está relacionado ao lugar da coletividade, onde se processam os temas relativos à vida em comum dos cidadãos. Assim, espaço público é tanto o espaço físico comum, a rua, a praça, a cidade, como
} 
público investiu em várias iniciativas governamentais para a inserção da administração pública no ambiente virtual. Tais ações representaram, inicialmente, o que se convencionou denominar de governo eletrônico, o qual é,

[...] uma infra-estrutura única de comunicação compartilhada por diferentes órgãos públicos a partir da qual a tecnologia da informação e da comunicação é usada de forma intensiva para melhorar a gestão pública e o atendimento ao cidadão. Assim, o seu objetivo é colocar o governo ao alcance de todos, ampliando a transparências das suas ações e incrementando a participação cidadã (ROVER, 2006, p.99).

Percebe-se a importância da comunicação nesse âmbito, uma vez que um dos objetivos do governo eletrônico seria racionalizar procedimentos, promover a interoperabilidade $^{2}$ e ser estruturado visando o melhor atendimento dos interesses dos cidadãos. Cabe ressaltar que esse conceito não fica adstrito à concepção apenas de informartização de documentos, como destacado por Ricardo Piana (2007, p.112):

El gobierno electrónico más que TIC aplicadas a los servicios existentes, es una forma de organización compleja y participativa que tiene varias dimensiones e implica una serie de acciones entre las que se destacan la digitalización y puesta en línea de los servicios ya existentes, la creación de nuevos servicios y programas y la participación ciudadana en la gestión del Estado e el Gobierno ${ }^{3}$.

A conceituação, portanto, estaria atrelada a uma nova visão da maneira de governar, na qual a antiga concepção do cidadão enquanto cliente é substituída por sua percepção como ator social. Cidadão que deseja intervir na definição de políticas públicas, que exige resultados e participa dos processos decisórios, atuações que tem no acesso à informação pública a condição de possibilidade.

Apesar de muito promissor, o desenvolvimento do governo eletrônico exige investimentos estruturais, tecnológicos e de modificação da cultura das instituições, sem os quais esta iniciativa não conseguirá ultrapassar suas formas mais incipientes. Nesse sentido, Ernani Marques dos Santos e Nicolau Reinhard (2013, p.126) destacam que a implementação do governo eletrônico envolve três etapas: "presença na Internet através de informações

também as instituições através das quais uma sociedade pensa em si mesma e encaminha soluções aos seus problemas, o espaço da cidadania" (2012, p.100).

${ }^{2}$ Para melhor esclarecimento, cabe dizer que "a interoperabilidade pode ser entendida como uma característica que se refere à capacidade de diversos sistemas e organizações trabalharem em conjunto (interoperar) de modo a garantir que pessoas, organizações e sistemas computacionais interajam para trocar informações de maneira eficaz e eficiente" (BRASIL, 2015, p.3).

3 "O governo eletrônico mais que TIC aplicadas aos serviços existentes, é uma forma de organização complexa e participativa que tem várias dimensões e implica em uma série de ações entre as que se destacam a digitalização e virtualização dos serviços já existentes, a criação de novos serviços e programas e a participação cidadã na gestão do Estado e o Governo" [tradução livre]. 
básicas, capacidade de transação para indivíduos e empresas e transações integradas com a colaboração de diversas agências".

Esses são os estágios que devem ser desenvolvidos para que se implemente o governo eletrônico em qualquer esfera (federal, estadual ou municipal). A adoção desse modelo geralmente parte do uso incipiente das TIC, no qual o site é utilizado para a mera exposição de informações públicas (análogo a um mural de recados) até avançar para as formas mais sofisticadas e que permitirão a execução de serviços públicos, o que ocorrerá quando o portal permitir a transação.

Todas essas potencialidades evidenciam a importância do uso das tecnologias da informação e comunicação no setor público, o que justifica a afirmação de Vacas (2013, p. 228), para quem "el gobierno es una red, y por nuestro bien debería ser la red la más eficiente y coherente de todas, por lo tanto la tarea de gobierno consiste que el resto de las redes (sociales) deseen ser asimiladas ${ }^{4}$. . Portanto, a adoção de mecanismos adequados para implementar o governo eletrônico, os investimentos em tecnologias e na formação de recursos humanos capazes de entender os objetivos do governo eletrônico devem ser metas perseguidas pelos gestores públicos nessa quadra da história.

Os esforços voltados para a construção de um modelo adequado de governo eletrônico devem considerar que o acesso à informação, o direito de participação política e o exercício do controle social são direitos de todo o cidadão e o seu provimento não consiste em mera concessão do gestor público. O uso das tecnologias oferece potencial para que os cidadãos assumam maior protagonismo, já que as ações deixariam de partir exclusivamente dos gestores, para acolher também as propostas oriundas da participação popular, como destacado por Diéguez e Ríos (2013, p. 242)

[...] Resulta igualmente advertir que las diversas formas de penetración e inclusión de las TIC en las esferas gubernamentales y de la administración pública no sólo dan lugar a novedosas pautas de vinculación entre gobiernos y ciudadanos, sino que en muchas ocasiones, estos patrones de interacción también se desarrollan en forma recíproca e interdependiente y no necesaria o exclusivamente se encuentran dirigidos o coordenados desde el Estado. ${ }^{5}$

\footnotetext{
4 “O governo é uma rede, e para nosso bem deveria ser a rede mais eficiente e coerente de todas, uma vez que a tarefa do governo é propiciar que o resto das redes (sociais) desejem ser assimiladas" [tradução livre].

5 "Cabe igualmente advertir que as diversas formas de penetração e inclusão das TIC nas esferas governamentais e da administração pública não somente dão lugar a novas pautas de vinculação entre governos e cidadãos, como em muitas ocasiões, esses padrões de interações também se desenvolvem em forma recíproca e interdependente e não necessária ou exclusivamente se encontram dirigidos ou coordenados desde o Estado" [tradução livre].
} 
Como se percebe, as tecnologias da informação e comunicação podem proporcionar a criação de um ambiente de mudanças materiais no mundo real, visando modificar o status quo da sociedade. O exercício cotidiano de novas formas de participação pode contribuir para que "a sociedade pense por si mesma em suas dificuldades, de maneira minimamente autônoma. Recria-se permanentemente a cena pública e, com ela, o espaço privado" (ROVER, 2006, p.93).

Essa transformação, no entanto, depende de um caminho de mão dupla, que envolve gestores e cidadãos. Com efeito, não se trata apenas de investimentos em tecnologia, mas na mudança de padrões comportamentais que devem ser transformados, processo que abarca todos os atores sociais e políticos, pois "las nuevas tecnologías, baratas y sencillas de manejar a todos, han cambiado las reglas del juego, pero no el juego en sí ${ }^{6}$ " (VACAS, 2013, p.229).

As tecnologias consistem em um instrumento que pode ser utilizado para melhorar o processo de tomada de decisões políticas, incrementando a comunicação e aperfeiçoando a prestação de contas públicas, mas por si só não podem ser vistas como responsáveis pelas transformações na democracia. Como bem salienta Pinho (2008, p. 473), “a abertura por parte dos governos para a transparência e participação societal depende de todo um processo histórico e do balanço de forças políticas existentes na sociedade, não ficando restrito a uma questão de tecnologia".

Essa compreensão é essencial para evitar a adoção de posturas ingênuas, que creditem ao mero uso de TIC o poder de, por si só, realizar as transformações políticas, tão necessárias e urgentes para tornar as instituições públicas mais transparentes e permeáveis ao controle social, advertência também lançada por Pinho (2008, p. 475), para quem "as TICs contêm um enorme potencial democrático, desde que haja definição política no sentido da participação popular e da transparência, pois o governo pode deixar de oferecer o que não quer mostrar, para nem mencionar o que quer esconder". Logo, a depender de seu uso, as tecnologias tanto podem servir para a manutenção dos velhos padrões de gestão, quanto podem significar uma verdadeira viragem no modelo de administração pública.

Era preciso ampliar a compreensão das potencialidades políticas ofertadas pelo uso de tecnologias, avançando de um modelo mais fechado e burocrático, no qual as TIC eram usadas apenas para melhorar os fluxos internos de trabalho, rumo a um processo mais democrático, capaz de abrir inéditos canais de interação e interlocução entre a Administração Pública e a sociedade. A necessidade de ampliar o escopo da análise fez com que muitos

\footnotetext{
6 “As novas tecnologias, baratas e simples de se manejar a todos, modificaram as regras do jogo, mas não o jogo em si” [tradução livre].
} 
autores, dentre eles Diego Prandino Alves, avançassem do conceito de governo eletrônico para o de governança, no qual se confere destaque para a:

\begin{abstract}
Capacidade de implementação de políticas públicas voltadas à consecução e à otimização da gestão, à adoção de métodos de avaliação, controle, e responsabilização, à prevenção de riscos e à correção de desvios, visando a promover a eficiência e a transparência institucionais e a participação e o bem-estar da sociedade (ALVES, 2011, p.235).
\end{abstract}

Percebe-se, portanto, a mudança estrutural contida nessa concepção de governança, pois seu fim primeiro e último é o bem-estar da sociedade, que se torna partícipe da gestão pública, superando os históricos antagonismos entre sociedade e Estado. Dessa maneira, muito mais que informatizar procedimentos, virtualizar informações e disponibilizar serviços on-line, essa nova percepção se preocupa com os rumos da democracia, principalmente no que diz respeito a resgatar a legitimidade da representação no sistema político atual. Essa viragem revela que, "o foco da atuação se expande em direção ao conjunto da sociedade, não se limitando a uma perspectiva voltada unicamente ao ambiente interno do governo" (PRADO; RIBEIRO; DINIZ, 2013, p.16).

A ampliação no conceito traz consigo a promessa de superação da visão do cidadão como cliente para, a partir do incremento de sua participação política, percebê-lo como ator fundamental da democracia. Dessa forma:

O conceito de e-governança pode e deve incluir a melhoria da eficiência e da eficácia, mas a elas não se resume; e-governança é o exercício de uma nova forma e de uma nova possibilidade de governar, com a participação de uma ampla rede de atores (CUNHA, MIRANDA, 2013, p.547).

Esse novo modelo pressupõe o reconhecimento, por parte do Estado, da diversidade social e da pluralidade de demandas que a sociedade plural e complexa do século XXI apresenta. Para além desse reconhecimento, a governança exige que o Estado abra canais de diálogo e interação a partir dos quais os atores sociais possam se expressar, propor programas, políticas públicas e exercer o controle da gestão. É nesse sentido que também se manifesta Pierre Calame (2009, p.92) para quem:

Nuevas formas de compromiso social, ejecución privada de funciones que hasta ahora eran prerrogativa de los Estados, refundación de la comunidad, redefinición de la ciudadanía, enfoque pragmático del Estado y de sus relaciones con la sociedad, desinstitucionalización, pluralismo jurídico, redescrubimiento del território, nuevas formas de relación entre niveles de gobernanza y construcción del escenario público internacional mediante iniciativas de la sociedad civil: son todas 
innovaciones pragmáticas que poco a poco van armando un sistema para contribuir a definir los contornos de la nueva gobernanza ${ }^{7}$.

Portanto, essa nova governança baseia-se na verdadeira comunicação entre gestores e cidadãos e para isso os canais de interação desempenham um papel essencial, “[...] abrindo um espaço de interlocução muito mais complexo e ampliando o grau de responsabilidade de segmentos que sempre tiveram participação assimétrica na gestão da coisa pública" (GRUMAN, 2008, p.103).

Essas potencialidades são inegáveis. No entanto, sabe-se que há uma larga distância entre as construções teóricas e a efetiva criação desses canais de interação nos órgãos públicos. Diante desse descompasso e visando oferecer uma visão mais realista da realidade, especialmente considerando o que determina a Lei de Acesso à Informação (LAI), na próxima seção serão apresentados e analisados os canais de participação e interação existentes nos portais das Universidades Públicas federais brasileiras. A escolha por este objeto de análise se justifica, pois além de essas instituições se sujeitarem aos princípios de transparência ativa e passiva determinados pela LAI, a sua função educativa e de formação de cidadãos lhes impõe postura ainda mais permeável à participação e ao controle social.

\section{O DIREITO DE ACESSO À INFORMAÇÃO NAS UNIVERSIDADES PÚBLICAS BRASILEIRAS COMO MECANISMO PARA DEMOCRATIZAR AS INSTITUIÇÕES DE ENSINO.}

A ideia de governança democrática e participativa tem como pressuposto o direito de acesso à informação pública por parte dos cidadãos. Este direito integra o rol de direitos fundamentais desde a Constituição Federal de 1988, constando no art. $5^{\circ}$, inciso XXXIII. ${ }^{8}$ Esta previsão também se coaduna com o princípio da publicidade, um dos vetores da Administração Pública, constante no artigo 37 da Carta Magna9, o que demonstra que "el

\footnotetext{
7 "Novas formas de compromisso social, execução privada de funções que até agora eram prerrogativas dos Estados, refundação da comunidade, redefinição da cidadania, enfoque pragmático do Estado e de suas relações com a sociedade, desinstitucionalização, pluralismo jurídico, redescoberta do território, novas formas de relação entre níveis de governança e construção de cenário público internacional mediante iniciativas da sociedade civil: são todas inovações pragmáticas que pouco a pouco vão armando um sistema para contribuir na definição dos contornos da nova governança" [tradução livre].

${ }^{8}$ Art. $5^{\circ}$, inciso XXXIII: Todos têm direito a receber dos órgãos públicos informações de seu interesse particular, ou de interesse coletivo ou geral, que serão prestadas no prazo da lei, sob pena de responsabilidade, ressalvadas aquelas cujo sigilo seja imprescindível à segurança da sociedade e do Estado (BRASIL, 1988).

9 Art. 37: A administração pública direta e indireta de qualquer dos poderes da União, dos Estados, do Distrito Federal e dos Municípios obedecerá aos princípios de legalidade, impessoalidade, moralidade, publicidade e eficiência (BRASIL, 1988).
} 
derecho a la información está sólidamente fundado en los principios básicos de la democracia, el buen gobierno y la participación ciudadana ${ }^{10 "}$ (ACKERMAN; SANDOVAL, 2005, p.15).

$\mathrm{O}$ direito de acesso à informação pública é condição para viabilizar a participação consciente e informada dos cidadãos no funcionamento das instituições públicas, devendo ser incentivada pelo Estado, cujas funções se transformam nessa quadra da história, conforme destacado por Galindo (2012, p. 37),

[...] el Estado de Derecho actual no es el Estado liberal del siglo XIX que limitaba la acción de los organismos públicos a actuar políticamente como policía elaborando las correspondientes leyes básicas y aplicándolas mediante penas o sanciones a los infractores del orden jurídico: salvaguardando el funcionamiento del mercado, sus posibles violaciones, sino que el Estado es, a la vez, Estado social, democrático, del bienestar, de la gobernanza y, hoy, el Estado propio de la denominada sociedad del conocimiento, que tiene potestad para participar en prácticamente todas las actividades diarias, especialmente las propias de las instituciones públicas una vez están financiadas con fondos públicos.

Na mesma linha segue Barroso (2011, p. 92), para quem o acesso à informação pública, por parte da sociedade contribui para “[...] prover mecanismos que garantam a boa administração, com racionalidade e transparência nos processos de tomada de decisão, de modo a propiciar governos eficientes e probos" (BARROSO, 2011, p. 92).

Gruman (2012, p. 101) também partilha da mesma posição, defendendo que o acesso à informação pública contribuirá para superar as assimetrias entre os agentes de Estado e a população, tornando-se visível “[...] o que está oculto nas ações governamentais”, o que associa direito à informação com transparência e prestação de contas da gestão pública.

Para impulsionar esse desvelamento dos atos foi promulgada no Brasil a Lei $\mathrm{n}^{\circ}$ 12.547/2011, denominada de Lei de Acesso à Informação (LAI).

Seu âmbito de aplicação é bastante amplo, pois além abranger a União, Estados, Distrito Federal e Munícipios, em todos os poderes, ainda abarca "autarquias, as fundações públicas, as empresas públicas, as sociedades de economia mista e demais entidades controladas direta ou indiretamente pela União, Estados, Distrito Federal e Municípios" (BRASIL, 2011) tendo plena incidência sobre as universidades, objeto de análise neste artigo.

Ao assim dispor a lei brasileira atendeu às sugestões que eram oferecidas pelos estudiosos do tema, como John M. Ackerman e Irma E. Sandoval (2005, p.24), para quem:

\footnotetext{
10 “O direito à informação está solidamente fundamentado nos princípios básicos da democracia, o bom governo e a participação cidadã” [tradução livre].
} 
Un escenario ideal estaría dado por una ley que cubra todas las instituciones que reciben dinero público, incluyendo los tres poderes de gobierno, los organismos autónomos, las organizaciones no gubernamentales, los individuos, los contratistas privados y los fideicomisos. Una situación aún mejor sería la de una ley que abriera a escrutinio público cualquier "entidad" que desarrolle funciones cruciales para el interés público (por ejemplo hospitales privados, escuelas, prisiones, etc.) independientemente de si estas reciben o no financiamiento gubernamental ${ }^{11}$.

Assim, considerando o interesse coletivo da atividade desempenhada pelas universidades e levando em conta seu caráter público, nada mais adequado do que lhes exigir a implementação de mecanismos para promover a transparência ativa e passiva, níveis explicitados por Juan Ignacio Belbis (2013, p.6) nos seguintes termos:

\begin{abstract}
En una primera instancia una transparencia pasiva, donde los estados responden de forma reactiva a los pedidos de la sociedad sobre cierta información en particular, como queda claro en las legislaciones sobre acceso a la información pública. Y en segunda instancia, donde las iniciativas de datos abiertos vienen a ocupar un lugar, que es la transparencia activa, el estado brindando de forma proactiva datos e información de diferentes tipos, en formatos dinámicos y digitales para su reutilización por parte de la ciudadanía ${ }^{12}$.
\end{abstract}

É inegável que a crença nas instituições públicas depende de sua transparência e abertura, sendo essencial que os gestores promovam a inclusão da sociedade na arena política. O tratamento da informação pública como propriedade privada do gestor e a manutenção de posturas refratárias à participação social nos destinos das instituições criam "[...] um clima de ceticismo, descrédito e indiferença à estrutura do Estado. A transparência na gestão, aliada a outros instrumentos que reforcem o direito e a possibilidade real de fiscalização da máquina pública, é o antídoto desse cenário" (MARTINS, 2011, p. 234).

Portanto, a transparência na gestão deve ser compreendida como um instrumento a partir do qual poderão se desenvolver novas dimensões da cidadania. Para que isso ocorra, as informações prestadas (de maneira espontânea ou mediante demanda do cidadão) devem qualificar-se por serem completas, compreensíveis, verídicas e oportunas, atributos essenciais

\footnotetext{
11 "Um cenário ideal estaria dado por uma lei que cubra todas as instituições que recebem dinheiro público, incluindo os três poderes do governo, os organismos autônomos e as organizações não-governamentais, os indivíduos, os contratantes privados e fideicomisso. Uma situação ainda melhor seria a de uma lei que abriria a escrutínio público qualquer entidade que desenvolva funções cruciais para o interesse público (por exemplo, hospitais privados, escolas, prisões, etc) independentemente de se estas recebem ou não financiamento governamental" [tradução livre].

12 "Como uma primeira instância a transparência passiva, onde os estados respondem de forma reativa aos pedidos da sociedade sobre certa informação em particular, como fica claro nas legislações sobre acesso à informação pública. E em segunda instância, aonde as iniciativas de dados abertos vem ocupar um lugar, que á transparência ativa, o estado brindando de forma proativa dados e informação de diferentes tipos, em formatos dinâmicos e digitais para sua reutilização por parte da cidadania” [tradução livre].
} 
para permitir o controle social e a democratização das universidades, conforme destacado por Boaventura de Sousa Santos (2005, p.77):

\begin{abstract}
A necessidade de uma nova institucionalidade de democracia externa é fundamental para tornar transparentes, mensuráveis, reguláveis e compatíveis às pressões sociais sobre as funções da universidade. E sobretudo para as debater no espaço público da universidade e torná-las objecto de decisões democráticas. Esta é uma das vias da democracia participativa para o novo patamar de legitimidade da universidade pública.
\end{abstract}

Com efeito, nos tempos atuais não se sustenta mais o modelo de universidade que se mantém encastelada na produção de um saber e de teorias que, embora de inegável valor científico, muitas vezes não têm o condão de se comunicar com a população, espelho desse cenário é a prática ainda não tão ampla de ações de extensão. Cada vez mais se reclama a abertura de novos espaços para que as estas instituições sejam capazes de acolher a pluralidade, dando voz aos mais diferentes atores. Junto à demanda por maior representatividade se editam pedidos de prestação de contas sobre a gestão interna dessas instituições, o que tem tido impulso nos últimos anos graças à vigência da Lei de Acesso à Informação.

Parte dessas mudanças foi desencadeada a partir da crescente utilização das tecnologias da informação e comunicação, ferramentas que se apresentam como um poderoso aliado da população nesse processo, o que inclusive é destacado no artigo $3^{\circ}$ da LAI. Fazendo uso de TIC o cidadão poderá obter as informações divulgadas espontaneamente nos portais dos órgãos públicos (com destaque para as universidades), assim como lhe será oportunizado manter contato com os gestores por meio dos canais de comunicação (a exemplo do e-SIC), o que pode ser feito de maneira rápida, sem necessidade de deslocamento físico e praticamente sem custos financeiros.

Essas facilidades transformam o cenário das instituições públicas, o que leva José Antonio Gomes de Pinho (2011, p. 98) a afirmar que:

\footnotetext{
Quando se fala em política, dois ramos são obrigatórios para análise: de um lado, o Estado, por meio de suas estruturas e como estas se adaptam à utilização da internet no sentido de promover a participação, interatividade, transparência e democratização de processos. De outro, a sociedade em seus movimentos no sentido de atuação política e suas interações com o Estado exercendo um juízo crítico e participativo.
}

O ambiente político, por conseguinte, é reforçado pelo acesso à informação, estimulando "a participação popular e se torna exercício de poder mais transparente e, 
portanto, mais democrático. Evita-se que o cidadão desinformado dos assuntos públicos se constitua num idiótes (conforme a nomenclatura dos gregos)" (LIMBERGER; SALDANHA, 2013, p.229).

Nessa senda, imprescindível instrumentalizar o cidadão para que exija dos gestores uma boa governança pública, conforme exposto no primeiro capítulo, e isso inclui as universidades federais. Logo, a verificação da existência de canais de comunicação se faz necessária para compreender o estado da promoção da transparência passiva nas universidades públicas federais, objeto de atenção no próximo tópico.

\section{ANÁLISE DOS PORTAIS DAS UNIVERSIDADES FEDERAIS: OS CANAIS DE COMUNICAÇÃO COMO FATOR DE IMPLEMENTAÇÃO DA GOVERNANÇA.}

O desenvolvimento da boa governança pública voltada ao atendimento dos interesses coletivos e à concretização de direitos depende, em grande parte, da existência de canais de comunicação entre as instituições e sociedade. Esta é uma exigência que se impõe às universidades públicas, também abrangidas pela Lei 12.527 de 2011.

Para realizar a análise da comunicação nos portais das universidades federais utilizouse formulário elaborado com base na LAI e cartilhas criadas do Poder Executivo. A observação foi estruturada e não participativa em páginas de 25 universidades públicas federais ${ }^{13}$ listadas como autarquias no relatório de integrantes do Sistema de Administração dos Recursos de Tecnologia da Informação (SISP) do portal de governo eletrônico ${ }^{14}$, realizada entre os dias 23 a 30 de novembro de $2014^{15}$.

$\mathrm{O}$ que justifica este trabalho no que se refere à verificação dos instrumentos para a efetivação da transparência passiva nas universidades federais é que, segundo relatório da Controladoria Geral da União (2013, p.47), o maior número de omissões dentro do Poder

\footnotetext{
13 A listagem completa das universidades analisadas é: Universidade Federal da Bahia; Universidade Federal da Paraíba; Universidade Federal de Alagoas; Universidade Federal de Campina Grande; Universidade Federal de Goiás; Universidade Federal de Itajubá; Universidade Federal de Juiz de Fora; Universidade Federal de Lavras; Universidade Federal de Minas Gerais; Universidade Federal de Pernambuco; Universidade Federal de Santa Catarina;Universidade Federal de Santa Maria;Universidade Federal de São Paul o;Universidade Federal de Uberlândia;Universidade Federal do Ceará;Uni versidade Federal do Espírito Santo;U niversidade Federal do Pará;Universidade Federal do Paraná;Universidade Federal do Rio de Janeiro;Universida de Federal do Rio Grande do Norte;Universidade Federal do Rio Grande do Sul;Universidade Federal Fluminens e;Universidade Federal Rural da Amazônia;Universidade Federal Rural de Pernambuco;Universidade Federal R ural do Rio de Janeiro.

${ }^{14} \mathrm{O}$ relatório pode ser acessado no link: www.governoeletronico.gov.br/biblioteca/.../orgaos-integrantes-do-sisp/

${ }^{15}$ Cabe ressaltar que o foco deste trabalho não foi analisar se há efetiva resposta das universidades aos pedidos de informação, tampouco o tempo despendido para essa resposta, uma vez que a observação foi não participativa.
} 
Executivo Federal provém das universidades e institutos federais de ensino, responsáveis por 486 das 985 situações em que não houve resposta às demandas sociais por informação. Esse dado demonstra como ainda as universidades estão longe de implementar a LAI de forma satisfatória no que concerne aos pedidos de acesso à informação. Como ação da Controladoria "foram cientificados 24 reitores para que adotassem providências para diminuir o quantitativo de pedidos ainda não respondidos. Após prazo estipulado, houve redução de aproximadamente $30 \%$ nas omissões" (2013, p.47). Percebe-se, portanto, que é possível a redução do número de omissões quando há um esforço dos gestores das universidades para de fato responder as demandas sociais. Por outro lado, também é notória a resistência desse segmento em mostrar-se permeável ao controle social, pois mesmo após a notificação feita pela CGU ainda há um grande número de universidades que não adotaram iniciativas para reverter o quadro de omissão.

Dito isso, a fim de sistematizar a exposição dos resultados obtidos pela observação, a análise será apresentada agrupando-se os dados mais relevantes a partir de seis categorias: a) contato com a universidade via formulários online; b) disponibilização de ouvidoria judicial; c) existência de espaço virtual de debate; d) divulgação de outros meios de comunicação para parcela da população que não tem acesso à internet, e) a existência do e-SIC.

Assim, quando verificados os portais que continham Fale Conosco ou Ouvidoria, constatou-se que $11^{16}$ do total apresentavam os dois mecanismos de comunicação, embora em alguns casos o Fale Conosco fosse denominado de outras formas, como no caso da Universidade Federal da Bahia que intitulava "Comunicação institucional". Em todos os sites existia pelo menos um desses mecanismos, sendo que apenas a Universidade Federal Rural da Amazônia não tinha Ouvidoria, apenas Fale Conosco, e a Universidade Federal de Alagoas tinha contato apenas com a área de tecnologia da informação. Esse dado pode espelhar a perda de função do canal Fale Conosco nos portais, o que ocorreu após o advento da Lei 12.527 de 2011 que determinou a criação do Serviço de Informação ao Cidadão, com objetivos e funções semelhantes.

\footnotetext{
16 Universidade Federal da Bahia, Universidade Federal de Goiás, Universidade Federal de Juiz de Fora, Universidade Federal de Pernambuco, Universidade Federal de Santa Catarina, Universidade Federal de São Paulo, Universidade Federal do Espírito Santo, Universidade Federal do Pará, Universidade Federal do Rio Grande do Norte, Universidade Federal de Pernambuco, Universidade Federal Rural do Rio de Janeiro.
} 
Como segunda categoria de análise, questionou-se: o local da solicitação de pedido (formulário) ${ }^{17}$ apresenta a necessidade de identificação do requerente e a especificação da informação requerida?

Como se sabe, a identificação e especificação da informação são mandamentos da LAI, em seu artigo 10, no qual "qualquer interessado poderá apresentar pedido de acesso a informações aos órgãos e entidades referidos no art. $1^{\underline{0}}$ desta Lei, por qualquer meio legítimo, devendo o pedido conter a identificação do requerente e a especificação da informação requerida" (BRASIL, 2011). Também é essa a estipulação do Decreto 7.724 de 2012, em seu artigo 12, segundo o qual, além dos requisitos da LAI, pedido de informação deve conter "o endereço físico ou eletrônico do requerente, para recebimento de comunicações ou da informação requerida" (BRASIL, 2012).

A observação estruturada permitiu constatar que $18^{18}$ portais requeriam a especificação desta informação para envio da comunicação. Embora alguns portais solicitassem a identificação do requerente, 8 portais tinham a possibilidade de anonimato no envio do formulário. A Universidade Federal do Rio Grande do Sul mantinha em destaque a impossibilidade do anonimato, em vista da previsão constitucional, no artigo $5^{\circ}$, inciso IV, o qual dispõe que "é livre a manifestação do pensamento, sendo vedado o anonimato" (BRASIL, 1988), explicitando que a manifestação anônima será armazenada, ou seja, sequer lida. A Universidade Federal de Pernambuco, por sua vez, exigia um amplo cadastro prévio para que o requerente pudesse acessar a área do formulário, com pedido de nome, telefone, endereço, CPF e e-mail do requerente, exigências que em certa medida podem inibir a participação do cidadão, que pode temer pela segurança de seus dados pessoais disponibilizados.

Uma informação interessante foi obtida no portal da Universidade Federal de Campina Grande, a qual justificava a possibilidade de anonimato em vista de normativa da Controladoria Geral da União de 2014. Tal instrução registra em seu artigo $1^{\text {o }}$ a seguinte previsão:

\footnotetext{
Art. $1^{\circ}$. Esta Instrução Normativa regulamenta o tratamento de manifestações anônimas e solicitações de reserva de identidade no âmbito dos órgãos de controle do Poder Executivo federal.

$\S 1^{\circ}$ Para fins desta instrução normativa, considera-se:
}

\footnotetext{
${ }^{17}$ Nesse ponto, insta ressaltar que foram considerados os formulários das Ouvidorias quando inexistente o Fale Conosco no portal analisado.

${ }^{18}$ A Universidade Federal Rural da Amazônia foi a única instituição que não foi possível avaliar essa questão,
} 
I - denúncia anônima: manifestação que chega aos órgãos e entidades públicas sem identificação;

II - reserva de identidade: hipótese em que o órgão público, a pedido ou de ofício, oculta a identificação do manifestante (BRASIL, 2014).

No que se refere à reserva de identidade, $9^{19}$ portais apresentavam a possibilidade de sigilo. Já a possibilidade de anonimato, com essa instrução, tornou-se um foco de amplas diferenças entre os portais, principalmente em vista da previsão constitucional de vedação do anonimato e a instrução da LAI em pedir a identificação do requerente. $\mathrm{O}$ artigo $2^{\circ}$ da instrução do CGU dispõe que "apresentada denúncia anônima frente à ouvidoria do Poder Executivo federal, esta a receberá e a tratará, devendo encaminhá-la aos órgãos responsáveis pela apuração desde que haja elementos suficientes à verificação dos fatos descritos" (BRASIL, 2014).

O que a identificação do solicitante permite é a resposta do órgão ao cidadão, ou seja, uma forma de efetivamente dar retorno à demanda. Por outro lado, a possibilidade de se fazer denúncias por meio da Ouvidoria se fosse realizada com a identificação do requerente poderia inibir os cidadãos de fazê-lo. Uma alternativa viável seria a hipótese do sigilo, que resolveria o problema da vedação do anonimato e preservaria a identidade do denunciante.

Um ponto interessante é se existe a possibilidade de o cidadão acompanhar a tramitação de sua demanda valendo-se, para tanto, de formulário eletrônico. Nesse sentido, apenas $7^{20}$ portais permitiam a consulta do trâmite da sua solicitação. Na Universidade Federal de Pernambuco, embora exigisse cadastro prévio, o registro e acompanhamento da demanda é bem organizado e utiliza uma escala de cores no processo de análise das demandas (registrada, reaberta, analisando, aguardando, resposta, encaminhada, respondida), o que permite que o demandante rapidamente identifique em que estado se encontra o seu pedido.

O acompanhamento da tramitação da requisição é muito importante para o cidadão e demonstra o respeito e a preocupação da instituição pública em promover a transparência em seus portais, constituindo-se em medida necessária para que se desenvolva a confiança da sociedade nessas formas de contato com os gestores públicos.

Essas medidas facilitadoras também podem contribuir para reverter as resistências que alguns internautas ainda têm em utilizar os serviços e governo eletrônico, pois conforme

\footnotetext{
${ }^{19}$ Universidade Federal de Pernambuco, Universidade Federal de Santa Catarina, Uni versidade Federal de Santa Maria, Universidade Federal de Uberlândia, Universidade Federal do Espírito Santo, Universidade Federal do Paraná, Universidade Federal do Rio de Janeiro, Universidade Federal do Rio Grande do Sul, Universidade Federal Fluminense.

${ }^{20}$ Universidade Federal de Lavras, Universidade Federal de Pernambuco, Universidade Federal de Santa Maria, Universidade Federal de São Paulo, Universidade Federal do Pará, Universidade Federal do Rio de Janeiro, Universidade Federal do Rio Grande do Sul.
} 
demonstrado pelos dados publicados na Pesquisa TIC Domicílios e Empresas (BRASIL, 2013), 9\% dos entrevistados informou que não usa esses serviços porque não recebe retorno de suas solicitações.

Nesse sentido, percebe-se que o investimento nos meios de contato online, principalmente no desenvolvimento de mecanismo de acompanhamento da demanda e o cumprimento dos prazos para resposta pelos servidores públicos, concedidos sempre que não for possível conceder o acesso imediato à informação, presente no art. 11 da LAI ${ }^{21}$, reflete diretamente na confiança e eficácia da relação entre a população e as universidades.

O prazo de resposta das universidades também precisa ser reduzido, pois segundo Relatório da Controladoria Geral da União sobre os dois primeiros anos de implementação da LAI (BRASIL, 2013, p.38), essas instituições levaram em média 24 dias para atender às demandas, constituindo-se no maior lapso temporal dentro do Governo Federal, seguidos pelas Estatais, que demoraram 20 dias para responder aos pedidos de informação, Ministérios (16 dias) e Agências Reguladoras, que levaram 11 dias pra responder às demandas.

Quanto à existência de Ouvidorias, cabe lembrar que este órgão permite a comunicação direta do cidadão com a instituição, franqueando-lhe a oportunidade de apresentar suas sugestões, críticas e reclamações. Segundo Mello e Callegari (2012, p.7-8):

\begin{abstract}
Ela tem a função de defender os interesses do cidadão em face da instituição à qual está vinculada. Esta comunicação direta com o usuário (consumidor e cidadão) é importante para melhorar a imagem institucional e dar visibilidade ao processo de aprimoramento dos serviços prestados. Através da ouvidoria, a organização tem a oportunidade de transformar reclamações em oportunidades de melhoria.
\end{abstract}

Fica evidente a importância da Ouvidoria, principalmente em um portal de Universidade Pública, a qual é espaço de construção de conhecimento, em tese, de diálogo e democrático. Apesar disso, a observação realizada permitiu constatar que em três portais (da Universidade Federal de Alagoas, da Universidade Federal de Goiás e da Universidade

\footnotetext{
${ }^{21}$ Dispõe o art. 11 da LAI (BRASIL, 2011): “Art. 11.0 órgão ou entidade pública deverá autorizar ou conceder o acesso imediato à informação disponível.

$\S 1$ 1Não sendo possível conceder o acesso imediato, na forma disposta no caput, o órgão ou entidade que receber o pedido deverá, em prazo não superior a 20 (vinte) dias:

I - comunicar a data, local e modo para se realizar a consulta, efetuar a reprodução ou obter a certidão;

II - indicar as razões de fato ou de direito da recusa, total ou parcial, do acesso pretendido; ou

III - comunicar que não possui a informação, indicar, se for do seu conhecimento, o órgão ou a entidade que a detém, ou, ainda, remeter o requerimento a esse órgão ou entidade, cientificando o interessado da remessa de seu pedido de informação.

$\S 2^{\circ} \mathrm{O}$ prazo referido no $\S 1^{\circ}$ - poderá ser prorrogado por mais 10 (dez) dias, mediante justificativa expressa, da qual será cientificado o requerente”.
} 
Federal Rural da Amazônia) este órgão não constava, o que revela uma tendência de algumas instituições de ensino ainda se manterem refratárias ao diálogo com a sociedade.

A divulgação de estatísticas referentes ao trabalho desenvolvido na Ouvidoria também é fundamental para o controle social, já que o cidadão pode perceber quantas o tipo de demanda encaminhado, quantas manifestações foram respondidas e em quanto tempo. Apesar da importância dessas estatísticas para avaliar os avanços das universidades na implementação da LAI, apenas $8^{22}$ páginas investigadas disponibilizavam tais relatórios. E, além disso, desse número, apenas $3^{23}$ sites mantinham os dados atualizados. A página da Universidade Federal do Pará tinha link para consultar os relatórios, mas quando acessado exibia uma mensagem de “em breve”. Já a Universidade Federal do Rio Grande do Norte apresentava relatórios de 2003 e a Universidade Federal de Uberlândia de 2008. Logo, embora apresentassem as informações estatísticas, elas estavam muito desatualizadas e não serviam aos propósitos do controle social.

Ao investigar a existência de espaço virtual de debate ${ }^{24}$ constatou-se que apenas $7^{25}$ dos portais analisados não apresentavam nenhum meio de debate virtual. Os outros portais geralmente disponibilizavam Twitter e Facebook, o que demonstra o crescimento do uso de redes sociais no cenário político. Nesse quesito registre-se que a Universidade Federal de Santa Catarina disponibilizava, além do Twitter e do Facebook, o Google+. Apesar de fazer menção às redes sociais, em nenhum portal constatou-se a presença de blog institucional.

Outro elemento analisado na pesquisa foi se algum dos portais apresentava atendimento on-line, o que resultou em resposta negativa, já que nenhuma dos sites institucionais apresentava esse recurso. O chat é uma ferramenta importante quando o usuário precisa de resposta imediata diante de algum problema enfrentado ao utilizar o portal ou da dificuldade em encontrar determinada informação.

A inexistência de canais de ajuda instantânea pode afastar o cidadão do portal institucional, fazendo-o deslocar-se fisicamente até os órgãos, o que frustrará os objetivos de governança eletrônica, o que indica que é mais rápido e útil oferecer bons serviços de ajuda instantânea, como chats, pois isso pode minimizar o tempo de atendimento no "balcão de

22 Universidade Federal de Goiás, Universidade Federal de Lavras, Universidade Federal de Uberlândia, Universidade Federal do Espírito Santo, Universidade Federal do Paraná, Universidade Federal do Rio de Janeiro, Universidade Federal do Rio Grande do Norte, Universidade Federal de Pernambuco.

${ }^{23}$ Universidade Federal de Goiás, Universidade Federal de Lavras, Universidade Federal do Espírito Santo.

${ }^{24}$ Nessa pesquisa o YouTube não foi considerado um espaço de debate público, pois embora tenha espaço para comentários na página, tem finalidades distintas das outras formas de interação para o debate.

${ }^{25}$ Universidade Federal de Pernambuco, Universidade Federal de Santa Maria, Universidade Federal de São Paulo, Universidade Federal de Uberlândia, Universidade Federal do Espírito Santo, Universidade Federal do Rio Grande do Sul. 
atendimento" dos diversos órgãos e departamentos existentes nas universidades. A existência de bons mecanismos de contato online também ajudaria na superação de outro problema manifestado pelos internautas que participaram da Pesquisa TIC Governo Eletrônico, segundo a qual "a maior parte dos usuários de Internet declarou que não utiliza os serviços de e-Gov porque prefere fazer contato pessoalmente com o órgão público (63\%)" (BRASIL, 2013, p. 160). A existência de bons serviços de contato instantâneo poderia se constituir em aliado, reduzindo deslocamento físico para o cidadão ao mesmo tempo que permitiria melhor organização do fluxo de trabalho para os servidores.

O último aspecto verificado na observação direta e estruturada refere-se à existência de e-SIC nos portais das universidades. Este serviço,

[...] possibilita que o solicitante, além de fazer o pedido de informação, acompanhe seu prazo de atendimento usando o número de protocolo gerado; consulte as respostas fornecidas pela administração; entre com recursos; e apresente reclamações (BRASIL, 2013, p.9).

Este item alcançou uma avaliação positiva na análise, pois todos os portais o apresentavam. Tal dado pode ser explicado porque o link do e-SIC remete a um sistema único de resposta do Poder Executivo Federal ${ }^{26}$. Dessa forma, o procedimento em todos os portais analisados é o mesmo, qual seja, um prévio cadastro com fornecimento de nome, CPF e email, dados obrigatórios para usar o sistema. Após o cadastramento, é possível acessar o formulário, sendo necessário informar o nome, órgão superior ou vinculado, a forma de recebimento de resposta (e-mail, correspondência com custo ou consulta pessoal), resumo e detalhamento da situação. Neste serviço também é possível anexar arquivos e há a possibilidade de o cidadão realizar o acompanhamento da tramitação de sua demanda, bem como lhe é permitido consultar eventuais recursos interpostos.

Esse cenário constatado nos portais das universidades federais demonstra que as instituições públicas de ensino ainda não se encontram completamente adequadas ao que determina a Lei de Acesso à Informação, revelando a persistência de posturas herméticas ao controle social. Tal distanciamento fere os princípios que inspiram o Estado democrático de Direito e impede que as universidades implantem modelos de gestão mais participativos e adequados às exigências da governança eletrônica.

\footnotetext{
${ }^{26}$ A página é remetida para o link:

http://www.acessoainformacao.gov.br/sistema/site/index.html?ReturnUrl=\%2fsistema\%2f.
} 


\section{CONCLUSÃO}

O uso das tecnologias da informação e comunicação oferecem grandes potenciais parra transformar a cultura das instituições universitárias, o que já se encontrava presente desde as primeiras iniciativas de governo eletrônico, cujo foco centrava-se na informação unidimensional, preparada e fornecida pelos gestores, e na maximização dos serviços públicos, com inegável potencial transformador quando se avança no sentido de governança eletrônica.

A partir da governança eletrônica a ênfase passa a ser dada aos processos de participação e interação da sociedade com os gestores, avançando-se de um modelo unidimensional para outro, mais democrático, transparente e permeável ao controle social, onde o foco passa a ser o cidadão.

Governança pressupõe acesso à informação, emancipação do cidadão e a criação de canais de comunicação eficientes entre administradores e administrados. Parte de uma nova compreensão, na qual se abandona a ideia de que as informações produzidas no interior dos órgãos públicos pertencem aos gestores, rumo à cultura do acesso, entendendo-se que os verdadeiros titulares são os cidadãos. Se essa nova postura é desejável em todo e qualquer órgão público, notadamente a partir da vigência da Lei de Acesso à Informação, sua observância ganha especial relevo quando se analisa o papel das universidades públicas, instituições que desempenham a missão de fomentar a construção de conhecimentos, contribuindo para a formação de novas expressões da cidadania. Essa missão certamente exige atuação ainda mais comprometida das universidades, que devem incentivar e valorizar o diálogo e a participação da sociedade em seus processos, mantendo postura que valoriza a transparência ativa e passiva.

Apesar de se esperar essa abertura, sabe-se que muitas vezes essas instituições se mantêm distantes da sociedade, comprometidas com a manutenção das mesmas pautas e reprodutoras de velhas práticas, conforme foi possível constatar do comportamento adotado nos dois primeiros anos de vigência da LAI, quando as instituições públicas federais foram os que mais resistiram em responder às demandas da sociedade.

Essa postura hermética tanto revela um preocupante déficit de transparência quanto à gestão dos recursos públicos, quanto denuncia que as universidades, mesmo em pleno século XXI, ainda têm dificuldade de manter-se atenta e receptiva às novas demandas apresentadas por uma sociedade complexa e plural, que reclama a inclusão de parcelas da população que historicamente estiveram à margem dos bancos universitários, como negros, índios e pessoas com deficiência. 
Democratizar a universidade é pauta importantíssima na evolução da sociedade e esse caminho passa pela universalização do acesso à informação pública e pela disponibilização de formas de comunicação entre a universidade e a comunidade, meios sem os quais não se efetivará a participação, condição de possibilidade para a governança.

Ainda que essa afirmação seja facilmente corroborada no campo teórico e facilmente possa ser implementada a partir do uso das tecnologias da informação e comunicação, sua concretização encontra grandes resistências. Ao se analisar os portais das universidades públicas federais percebe-se que ainda há um caminho longo a ser percorrido na criação e manutenção de canais de comunicação entre as instituições e a sociedade. Cabe pontuar que o atual estudo esteve adstrito às universidades públicas federais que são consideradas autarquias, ou seja, há que se considerar os limites da análise nesse sentido, representando uma parte desse universo.

Como constatado pela observação empreendida, apenas uma ínfima parcela dos portais institucionais possibilita o acompanhamento das demandas apresentadas pelo cidadão nos canais de contato, o que evidencia as dificuldades de implementação da LAI, pois o demandante tem o direito de saber como e quando a administração pública vai processar e responder ao seu pedido de informação. Tal medida é de simples concretização, porém confere grande credibilidade ao processo, além de evitar que o cidadão se desloque até o setor para ver atendido o seu pedido.

Percebeu-se que há discrepâncias entre os portais institucionais quanto ao tratamento do anonimato, o que em parte se deve inclusive às contradições entre a instrução normativa da CGU, o dispositivo constitucional que veda o anonimato e as disposições da própria Lei 12.527 de 2011 sobre a identificação do requerente. Nesse caso acredita-se que a manutenção do sigilo sobre os dados do cidadão, quando por ele solicitado, seja a alternativa mais viável para harmonizar o conflito entre o anonimato e a publicização do nome. O sucesso dessa alternativa, no entanto, exige o comprometimento e a colaboração dos gestores em resguardar as informações do demandante.

Quando o exame recaiu sobre o e-SIC a avaliação foi positiva, evidenciando que quando há vontade política por parte dos gestores é possível viabilizar canais de diálogo com a sociedade. Nesse sentido constatou-se que a concentração de procedimentos administrativos em um só canal pode se constituir em interessante alternativa, pois a utilização de uma página única por todos os órgãos integrantes do Poder Executivo Federal permite que o cidadão esteja mais familiarizado com os mecanismos para ter acesso à informação. Uma vez 
compreendido em um site, todos os demais seguem a mesma sistemática, o que torna o sistema amigável.

É inegável que as soluções tecnológicas auxiliam o processo de abertura institucional rumo a um novo modelo de co-participação, mais democrático e transparente. No entanto, antes do aporte tecnológico, tal transformação passa pela mudança na cultura institucional, cujos gestores precisam compreender que a missão dessas instituições pressupõe sua abertura e comprometimento com o desenvolvimento de valores de cidadania, em estrito respeito aos princípios que orientam o Estado Democrático de Direito.

\section{REFERÊNCIAS}

ACKERMAN, John M.; SANDOVAL, Irma E. Leyes de Acceso a la Información en el mundo. Cuadernos de Transparencia, 07. Delegación Coyoacán, México, D.F.: Instituto Federal de Acceso a la Información Pública, 2005.

ALVES, Diego Prandino. Acesso à informação pública no Brasil: um estudo sobre a convergência e a harmonia existentes entre os principais instrumentos de transparência e de controle social. Disponível em:

<http://www.cgu.gov.br/concursos/Arquivos/6_ConcursoMonografias/Mencao-HonrosaProfissionais.pdf $>$. Acesso em: 12 ago. 2013.

BARROSO, Luís Roberto. Curso de Direito Constitucional Contemporâneo. Os conceitos fundamentais e a construção do novo modelo. São Paulo: Saraiva, 2010, $2^{a}$ Tiragem 2011.

BELBIS, Juan Ignacio. Del gobierno abierto a los datos abiertos. In: ELIZALDE, Luciano; RIORDA, Mario. Comunicación Gubernamental 360. Ciudad Autónoma de Buenos Aires: La Crujía, 2013, p. 269-282.

BRASIL. Constituição da República Federativa do Brasil: promulgada em 5 de outubro de

Decreto 7.724, de 16 de maio de 2012.

Regulamenta a Lei $\mathrm{n}^{\mathrm{o}}$ 12.527, de 18 de novembro de 2011, que dispõe sobre o acesso a informações previsto no inciso XXXIII do caput do art. $5^{\circ}$, no inciso II do $\S 3^{\circ}$ do art. 37 e no $\S$ $2^{\underline{0}}$ do art. 216 da Constituição. Disponível em:<http://www.planalto.gov.br/ccivil_03/_ato20112014/2012/decreto/D7724.htm>. Acesso em: 20 nov. 2014.

. Ministério do Planejamento, Orçamento e Gestão. Secretaria de Logística e Tecnologia da Informação. Padrões de Interoperabilidade de Governo Eletrônico. Brasília: MP, SLTI, 2015. 
. Lei $\mathrm{n}^{0}$ 12.527, de 18 de novembro de 2011. Regula o acesso a informações previsto no inciso XXXIII do art. 5o, no inciso II do $\S 30$ do art. 37 e no $§ 20$ do art. 216 da Constituição Federal; altera a Lei no 8.112, de 11 de dezembro de 1990; revoga a Lei no 11.111, de 5 de maio de 2005, e dispositivos da Lei no 8.159, de 8 de janeiro de 1991; e dá outras providências. Disponível em <http://www.planalto.gov.br/ccivil_03/_ato20112014/2011/lei/112527.htm>. Acesso em: 24 jul. 2014.

. Comitê Gestor da Internet no Brasil (CGI.br). Pesquisa sobre o uso das

tecnologias de informação e comunicação no Brasil [livro eletrônico]: TIC Domicílios e Empresas 2013 = Surveyonthe use ofinformationand c ommunicationtechnologies in Brazil : ICT HouseholdsandEnterprises 2013 / São Paulo: Comitê Gestor da Internet no Brasil, 2014. Disponível em: $<$ http://www.cetic.br/publicacao/pesquisa-sobre-o-uso-das-tecnologias-deinformacao-e-comunicacao-no-brasil-tic-domicilios-e-empresas-2013/> . Acesso em: 14 mar. 2015.

Comitê Gestor da Internet no Brasil (CGI.br). Pesquisa sobre o uso das

tecnologias de informação e comunicação no Brasil [livro eletrônico]: TIC Governo Eletrônico 2013 = Surveyonthe use ofinformationand c ommunicationtechnologies in Brazil : ICT electronic government 2013- São Paulo: Comitê Gestor da Internet no Brasil, 2014. Disponível em:<

http://www.cetic.br/media/docs/publicacoes/2/TIC_eGOV_2013_LIVRO_ELETRONICO.pd f>. Acesso em: 14 mar. 2015.

. Controladoria Geral da União (CGU). Relatório sobre a implementação da Lei 12.527 de 2011: Lei de Acesso à Informação - Poder Executivo Federal. [livro eletrônico]. Disponível em: $<$ http://www.acessoainformacao.gov.br/central-deconteudo/publicacoes/relatorio-2-anos-lai-web.pdf>. Acesso em: 25 nov. 2014.

. Controladoria Geral da União (CGU). Instrução Normativa 01/2014, de 24 de junho de 2014. Estabelece normas de recebimento e tratamento de denúncias anônimas e estabelece diretrizes para a reserva de identidade do denunciante. Disponível em:< http://www.cgu.gov.br/sobre/legislacao/arquivos/instrucoes-normativas/in-crg-ogu-012014.pdf>. Acesso em: 22 nov. 2014.

IVOSKUS, Daniel. Vivir conectados: sociedad, política y comunicación en la era digital. Buenos Aires: Grupo Digital Norma, 2008.

CALAME, Pierre. Hacia una revolución de la gobernanza: reinventar la democracia. Santiago: LOM Ediciones, 2009.

CASTELLS, Manuel. A sociedade em rede. São Paulo: Paz e Terra, 1999. 
. A Galáxia Internet: reflexões sobre Internet, Negócios e Sociedade.

Lisboa: Fundação Calouste Gulbenkian, 2004.

CUNHA, Maria Alexandra Viegas Cortez da; MIRANDA, Paulo Roberto de Mello. O uso de TIC pelos governos: uma proposta de agenda de pesquisa a partir da produção acadêmica e da prática nacional. Organ. Soc., Salvador, v. 20, n. 66, Sept. 2013 . Disponível em:< http://dx.doi.org/10.1590/S1984-92302013000300010.>. Acesso em: 18 Jul. 2014.

DIÉGUEZ, Gonzalo; RÍOS, Maximiliano Campos. ¿Hacia uma nueva configuración de las relaciones entre el gobierno y la cidadanía? Breves apuntes sobre el gobierno eletrônico. In: ELIZALDE, Luciano; RIORDA, Mario. Comunicación Gubernamental 360. Ciudad Autónoma de Buenos Aires: La Crujía, 2013, p. 241-250.

GALINDO AYUDA, Fernando. Democracia, internet y gobernanza: una concreción. Sequência (Florianópolis), Florianópolis , n. 65, dez. 2012 . Disponível em <http://www.scielo.br/scielo.php?script=sci_arttext\&pid=S2177-

70552012000200003\&lng=pt\&nrm=iso>. Acesso em 23 ago. 2013. http://dx.doi.org/10.5007/2177-7055.2012v33n65p33.

GRUMAN, Marcelo. Lei de Acesso à Informação: notas e um breve exemplo. Revista Debates, Porto Alegre, v.6, n.3, p.97-108, set./dez. 2012. Disponível em:< http://seer.ufrgs.br/index.php/debates/article/view/34229/23345> Acesso em: 10 mar. 2015.

LASH, Scott. Crítica de la información. Buenos Aires: Amorrortu, 2005.

LIMBERGER, Têmis; SALDANHA, Jânia Maria Lopes. Cibercidadania no mundo globalizado: o desafio das novas tecnologías e a concretização dos direitos humanos nas democracias contemporáneas. In: Anuário de Derecho Constitucional latinoamericano. Año XVIII, 2012, p.215-230, Bogotá.

MARTINS, Carlos Benedito. Uma reforma necessária. Educ. Soc., Campinas, v. 27, n. 96, p. 1001-1020, out. 2006. Disponível em <http://www.scielo.br/scielo.php?script=sci_arttext\&pid=S010173302006000300017\&lng=pt\&nrm=iso $>$. Acesso em: 21 ago. 2015.

MARTINS, Paula Lígia. Acesso à informação: um direito fundamental e instrumental. Acervo. v.24, n.1, jan-jun. 2011, p.233-244. Rio de Janeiro, 2011. 
MELLO, Celso Antônio Bandeira de. Curso de Direito Administrativo. 21.ed. São Paulo: Malheiros, 2006.

MELLO, Marcelo Pereira de; CALLEGARI, José Antonio. Ouvidoria: Direito

Fundamental de Acesso à Justiça e defesa da cidadania.In: CONGRESSO INTERNACIONAL INTERDISCIPLINAR EM SOCIAIS E HUMANIDADES. 2012, Niterói. Disponível em:

<http://www.aninter.com.br/ANAIS\%20I\%20CONITER/GT18\%20Acesso\%20\%E0\%20justi $\%$ E7a,\%20direitos $\% 20$ humanos $\% 20 \mathrm{e} \% 20$ cidadania/OUVIDORIA $\%$ 20DIREITO $\% 20$ FUND AMENTAL\%20DE\%20ACESSO \%20\%C0\%20JUSTI\%C7A\%20E\%20DEFESA\%20DA\%2 0CIDADANIA\% 20-\%20Trabalho\%20completo.pdf>. Acesso em: 22 jul. 2014.

OLIVEIRA, Luiz Ademir de; FERNANDES, Adélia Barroso. Espaço público, política e ação comunicativa a partir da concepção habermasiana. Revista Estudos Filosóficos, Minas Gerais, n.6, p.116-130, 2011. Disponível em:<http://www.ufsj.edu.br/portal2repositorio/File/revistaestudosfilosoficos/art8_rev6.pdf> Acesso em: 10 mar. 2015.

PIANA, Ricardo Sebástian. Gobierno Electrónico: governo, tecnologias y reformas. La Plata: Univ. Nacional de La Plata, 2007.

PINHO, José Antonio Gomes de. Sociedade da informação, capitalismo e sociedade civil: reflexões sobre política, internet e democracia na realidade Brasileira. Rev. adm. empres., São Paulo, v. 51, n. 1, fev. 2011. Disponível em $<$ http://www.scielo.br/scielo.php?script=sci_arttext\&pid=S0034$75902011000100009 \& \operatorname{lng}=$ pt\&nrm=iso>. acessos em 08 jul. 2013. http://dx.doi.org/10.1590/S0034-75902011000100009.

Investigando portais de governo eletrônico de estados no Brasil: muita tecnologia, pouca democracia. Revista de Adminis tração Pública, Rio de Janeiro, v.42, n. 3, p.471-493, maio/jun. 2008. Disponível em:< http://www.scielo.br/pdf/rap/v42n3/a03v42n3> Acesso em: 10 mar. 2015.

PRADO, Otávio; RIBEIRO, Manuella Maia; DINIZ, Eduardo. Governo Eletrônico e transparência: olhar crítico sobre os portais do governo federal brasileiro. In: PINHO, José Antonio Gomes de. (Org.). Estado, sociedade e interações digitais: expectativas democráticas. Salvador: EDUFBA, 2012, p. 13-40.

ROVER, Aires José. A democracia digital possível. Revista Seqüência, no 52, p. 85-104, jul. 2006. Disponível em:

<http://periodicos.ufsc.br/index.php/sequencia/article/view/15202/13827>.

Acesso em: 15 mar. 2012. 
SANTOS, Boaventura de Sousa. A universidade no século XXI: para uma reforma democrática e emancipatória da universidade. 2. ed. São Paulo: Cortez, 2005.

SANTOS, Ernani Marques dos; REINHARD, Nicolau. Disponibilização e uso dos serviços de governo eletrônico no Brasil: a visão dos usuários. In: PINHO, José Antonio Gomes de. (Org.). Estado, sociedade e interações digitais: expectativas democráticas. Salvador: EDUFBA, 2012, p. 119-136.

VACAS, Francisco. Gobierno y ciudadanía: nodos em la red. In: ELIZALDE, Luciano; RIORDA, Mario. Comunicación Gubernamental 360. Ciudad Autónoma de Buenos Aires: La Crujía, 2013, p. 221-240. 